\title{
Barriers and Enablers to Planning Initiatives for Active Living and Health
}

\author{
Anthony McCosker ${ }^{1} \&$ Anne Matan ${ }^{1}$ \\ ${ }^{1}$ Curtin University Sustainability Policy (CUSP) Institute, Curtin University, Perth, Australia \\ Correspondence: Anthony McCosker, Curtin University Sustainability Policy (CUSP) Institute, Curtin University, \\ GPO Box U 1987, Perth, Western Australia, Australia. E-mail: a.mccosker@postgrad.curtin.edu.au
}

Received: December 5, 2017

Accepted: December 27, 2017 Online Published: January 30, 2018

doi:10.5539/jsd.v11n1p68

URL: https://doi.org/10.5539/jsd.v11n1p68

\begin{abstract}
The response of local government (LG) to issues of rising rates of noncommunicable diseases (NCDs) is an important one given their roles as place managers. This article explores the experiences of LG built environment and community health practitioners to identify barriers and enablers to the implementation of healthy planning and associated active living promotion efforts. The role of Australian LG in community health is presented, followed by findings from practitioner surveys and policy analysis undertaken, with subsequent discussion of the barriers and enablers. Six key enablers and barriers to successful project implementation were identified: (1) internal LG functioning, (2) the promotion of co-benefits, (3) partnerships, (4) the value of recognition and good news, (5) placing a mandate for action on LG and (6) funding and resourcing.
\end{abstract}

Keywords: planning, health, active living, multiple streams analysis, Australia, local government

\section{Introduction}

Many developed countries are experiencing a rising prevalence of chronic NCDs. At the same time, in many of these places, there are persistent tensions surrounding urban government/governance systems (Allmendinger \& Haughton, 2013; Hambleton, 2011; Healey, 2010). Against this backdrop, LGs are increasingly having to address community health through changes to the built environment that encourage physical activity. In Australia this can be seen in knowledge translation programs for LG health promotion (see for example Pettman et al., 2013, 72-73), partial state devolution of community health responsibility to LG through Public Health Acts (Jolley \& Barton, 2015; Lawless, Lane, Lewis, Baum, \& Harris, 2017), and a concerted focus of advocacy group efforts towards LGs and LG practitioners (see for instance Butterworth, 2009; Wiggins, 2008; 2013). Academic attention has been given to planning for health (sometimes referred to as 'healthy planning') in Australia at the metropolitan and regional scales (Wheeler \& Thompson, 2010) and to state scale policy (Christian et al., 2013) and advocacy (Harris, Kent, Sainsbury, \& Thow, 2016). Given the localised way in which the built environment can impact health and health promoting activities such as physical activity (Ewing \& Handy, 2009; Frank, Andresen, \& Schmid, 2004), a study of the perspectives of practitioners involved in the delivery of healthy planning and active living initiatives at the LG level is necessary.

This article examines the experiences of LG built environment and community health practitioners in the field of healthy planning and associated active living promotion efforts to identify enablers and barriers to implementation using a multiple streams analysis (MSA) framework (Kingdon, 2003). Understanding of LG's role in Australia in community health is presented, followed by the findings of the practitioner surveys and policy analysis and discussion of the barriers and enablers.

The powers of LG in Australia are generally limited as they remain a 'creature' of the states; that is, Australian LGs find their 'role and purpose' being defined on a state-by-state (Note 1) basis through state legislation (Aulich, 2015, 163-164). As such, Australian LG can be viewed as 'a vehicle through which to deliver a range of services' rather than having 'importance as a political institution' (Grant, Dollery, \& Kortt, 2016, 1028). This limited role of LG in Australia with regard to other comparable levels of government globally is well-documented (Grant et al., 2016). Nevertheless, the devolution of certain powers from state governments, particularly planning and increasingly public health, leads LGs to have not just relevance but an increasingly important role if healthy planning and active living initiatives are to be successfully undertaken in Australia. Indeed, LGs globally have been noted to be increasingly concerned with 'international developments' (Hambleton, 2011, 10). Therefore, 
while the role of planning by LG in Australia has always been driven either implicitly or explicitly by considerations of public health (Freestone \& Wheeler, 2015; Giles-Corti et al., 2014), the remit of LG has arguably been extended to now include addressing global concerns including rising rates of NCDs such as obesity and other diseases related to low physical activity levels (Roberto et al., 2015). This idea of Australian LG's relatively broad remit is supported by Stoker (2011, 22), whose 'typology of local government societal functions' positions Australian LG as having an emerging 'lifestyle coordination' function, which 'involves local government systems stepping beyond welfare service provision and narrow support for economic development to a broader co-ordinating role in supporting citizens' changing and developing lifestyle choices.'

It is within this seemingly contradictory context, on one hand an expectation for LG 'not just to deliver certain services well but to steer a community to meet the full range of its needs' (Stoker, 2011, 17), and on the other relatively limited powers assigned to LG by the states (Aulich, 2015), that many healthy planning and active living initiatives are delivered in Australia. Despite the potential tensions caused by this situation, the important role of LG remains clear. The relationship between the built environment and physical activity (Matan, Newman, Trubka, Beattie, \& Selvey, 2015) and health (Rissel \& McCue, 2014) is firmly established, and in Australia, LG has a central role in various land use and built environment decisions (Williams \& Maginn, 2012).

Furthermore, a mandate and 'meaningful framework' exists for the role of LG across the world in this space, in the form of the World Health Organisation's Healthy Cities movement to implement the Ottawa Charter (1986) (Chapman \& Davey, 1997, 82). Healthy Cities (1987) encourages a socio-ecological perspective to be adopted in planning with community health as a central consideration (Chapman \& Davey, 1997; Lawless et al., 2017). A socio-ecological perspective involves consideration of both the ecological (i.e. environmental, biological and behavioural influences; Swinburn, Egger, \& Raza, 1999, 564) and social (i.e. culture, economics and politics; Stokols, 1992, 7) determinants of health. Browne, Davern, and Giles-Corti $(2016,126)$ identify the value of LG in having 'unique knowledge and capability to address' these determinants, as well as having a central role given that in Australia it is 'the level of government closest to the people'. The role of Australian LG in this field is important.

\subsection{Review of Relevant Literature}

Given the important role of LG as discussed above, understanding how healthy planning and active living initiatives come to be implemented, and the experiences of both community health and built environment practitioners in this implementation, is valuable knowledge (Allender, Cavill, Parker, \& Foster, 2009a). Nevertheless, until recently such an understanding has been relatively uncharted in the literature, especially at a local scale in an Australian setting (Browne et al., 2016; Lawless et al., 2017). In Australia, Lowe, Whitzman and Giles-Corti (2017) examine barriers and enablers to horizontally integrated health-promoting planning at the state government level in Victoria, with policy context, policy actors, policy processes and policy content given as relevant considerations. Thompson and $\operatorname{McCue}(2016,14)$ note the politicised nature of healthy planning at the state level in New South Wales, whereby 'an integrated, joined up and collaborative approach' enables health considerations to be incorporated into planning, and framing 'health [as] a core component of the planning process' is central to 'transcend[ing...] conceptual, institutional and social barriers' to partnership formation.

At a LG level, Allender et al.'s $(2011,266-267)$ study to determine the potential for support of policy interventions for healthy eating and physical activity in Victoria found 'general support' for walking and cycling environment changes and land use zoning/mix, as well as open space provision. Primary barriers to policy change in this study are noted as 'competing priorities and limited funding' (Allender et al., 2011, 268). Another study based in Victoria found that 'urban planning for mixed land use' was perceived as one of the least feasible obesity prevention program types by LG and other practitioners, a perception likely to act as a significant barrier to implementation of such programs (Cleland, McNeilly, Crawford \& Ball, 2013, E452). Lawless et al. (2017, 206), in their study of LG officers, found that approximately 45 percent of respondents in Australian LG roles where social determinants of health had relevance were unfamiliar or only moderately familiar with such concepts. Regarding project implementation, the study found that 'more practical information' regarding initiatives, 'new cross-sectoral government decision-making structures', greater requirements surrounding health impact assessments and further research would help practitioners (Lawless et al., 2017, 206). In another Victorian study, Allender et al. (2009b, n.p.n.) note enabling factors for a healthy environment (relating to both physical activity and healthy eating) to include changes that were 'supported by external funding, developed from a local evidence base and sensitive to community and market forces.' Barriers identified include 'a perceived or real lack of power to make change,' a complex legislative setting and 'a reluctance to increase regulation' (Allender et al., 2009b, n.p.n.). While the predominant focus of the above literature on a Victorian setting, and the absence of research with an Australia-wide scope is noted, these studies help set the context for 
this research.

In contrast to the relatively limited literature on implementation of healthy planning and active living initiatives by Australian LG, a burgeoning amount of non-academic guidance and advocacy has emerged in recent years. Such sources include online resources with specific information for planners at LG level (ALGA, National Heart Foundation of Australia, \& PIA, 2009), national online guides with tailored, state-specific guidance to practitioners (Healthy Active by Design, 2017), state-based guides for 'planning and designing environments for active living' (National Heart Foundation of Australia, 2009) and numerous other advocacy and practitioner tools (such as Lette, 2011; National Heart Foundation of Australia, 2012; NSW Department of Health, 2009; Premier's Council for Active Living, 2012). Yet while the attitudes and knowledge of LG professionals has been examined in some (predominantly) state-oriented studies, and the ever-growing guidance and advocacy is often targeted towards LGs and their practitioners, knowledge surrounding the barriers and enablers that allow or discourage implementation of healthy planning and active living initiatives at a LG level remains scarce. This research aims to help bridge these two knowledge streams and address this knowledge gap.

\section{Method}

Hambleton $(2011,28)$ states that 'radical change requires political, rather than managerial, thinking because significant shifts in power are necessary.' A framework that enables political considerations, particularly given the changing role for LG in Australia as outlined in Section 1, is necessary to understanding the barriers and enablers to implementation of healthy planning and active living initiatives. A need for research in this field to understand "policy world' realities' has also been noted (Giles-Corti, Sallis, Sugiyama, Frank, Lowe, \& Owen, 2015, 235), however no established methodology currently exists for such (Kurko \& Holden, 2012).

This research uses an exploratory approach combining surveys undertaken by LG practitioners around Australia with policy research. Findings from the surveys and policy analysis are then analysed through a MSA framework using three themes (problems/conditions, politics and policy). A MSA approach has been used in both the health (Tenbensel, Eagle, \& Ashton, 2012, p. 31) and built environment (Dudey, 2013) fields, while Lawless et al. (2017) note the relevance of policy agenda setting theories such as MSA to an Australian LG context and to community health. MSA frameworks enable understanding of why certain problems are addressed over others, why when multiple organisations (including LGs) are faced with comparable issues, different solutions are often chosen (Henstra, 2010) and how the three streams can be brought together through a concerted effort (creating a policy window). In the absence of a dominant policy theory or evaluative framework through which to examine initiative uptake in this emerging field, a MSA framework allows for a 'policy world' understanding (Giles-Corti et al., 2015), particularly necessary given the contested nature of healthy planning at the LG level.

\subsection{Sample}

Purposeful sampling was employed to identify LGs involved in implementation of healthy planning and active living efforts, in the form of the annual Heart Foundation (HF) Local Government Awards $(2014,2015)$ and Healthy Spaces and Places (HSAP) online case studies. Both feature cases of 'good practice' LG implementation of healthy planning and active living initiatives across Australia. Selection criteria for participation included that: each initiative must (1) be identified on either the HSAP website (as of 2 December 2015) and/or be featured within the HF Awards 2014 and/or 2015, (2) be a healthy planning and/or active living promotion initiative, and (3) have identified LG as the central actor. The sample therefore reflects the various biases of the sources (i.e. the HF Awards are awarded on a state-by-state and LG population size basis and involve self-nomination, and HSAP cases have been selected as an online resource of 'good practice' examples of these ideas being implemented). Nevertheless, purposive sampling is considered appropriate for exploratory research as undertaken, with the HF Awards and HSAP resource providing a suitable sample of LGs publicly identified as undertaking projects in this field, and providing pre-identified and completed or ongoing, LG-based initiatives for respondents to reflect on.

A total of 20 LGs participated (five identified from HSAP initiatives, five identified from HF 2014 Awards and 10 identified from HF 2015 awards). Of the 20 LG surveys returned, 11 were completed by community health practitioners and nine were completed by built environment practitioners, with 11 female and nine male respondents. Surveys were completed on behalf of respondents' LGs. Responses were returned from LGs from across South Australia (six), New South Wales (four), Victoria (three), Queensland (three), Tasmania (three) and the Northern Territory (one). Due to academic interest in the coming together of two previously (at least recently) disparate professions (Thompson, Kent, \& Lyons, 2013), responses are subsequently identified as being from community health $[\mathrm{CH}]$ or built environment $[\mathrm{BE}]$ practitioners. 


\subsection{Procedure}

Surveys were distributed via email across two rounds. Given the aims and iterative methods of this exploratory research, data saturation (Allender et al., 2009a) was used to gauge a point of suitable data collection, with additional data gathered beyond that point considered to produce only more data rather than increasing accuracy (Carter \& Little, 2007, 1321). Upon return, the respondents' LG's planning and strategic policy context, any additional attached information (non-requested but in some instances provided and referenced in survey responses) and the survey itself were analysed using data analysis software NVivo 11. Sensitising concepts from MSA informed the coding undertaken immediately following the return of each survey, with emergent themes identified. Use of sensitising concepts allows for an analysis lens to be proposed and tested, but avoids 'forcing data into pre-existing concepts and theories' (Thornberg, 2012, 249). Emergent themes were referred back to existing data to iteratively validate preliminary findings. Upon data saturation the identified themes were then further coded as being supportive (enablers), limiting (barriers) or having both supportive and limiting impacts (barriers and enablers) on project implementation in the experience of the practitioner (Note 2).

\subsection{Instruments}

The surveys were electronically distributed as Microsoft Word documents and comprised 17 open-ended, qualitative questions, with no word limit for responses. As discussed in Section 2.2, documents relating to each LG's planning and strategic policy context, and any ancillary files returned by respondents were also analysed. NVivo 11 software was used to analyse all data.

\section{Research Findings}

The national scope of this research enabled the identification of broad themes. As respondents' selection was based on successful cases of implementation, identification of enablers was more prevalent than barriers. Nevertheless, enablers to successful project uptake and barriers that were encountered in implementation were able to be discerned, with the study revealing six key themes: (1) internal LG functioning, (2) the promotion of co-benefits, (3) partnerships, (4) the value of recognition and good news, (5) placing a mandate for action on LG and (6) funding and resourcing. These are outlined below.

\subsection{Internal LG Functioning as both Barrier and Enabler}

The most commonly identified theme in influencing project uptake was the internal functioning of the LG. This theme was commonly noted as a potential barrier, but importantly was recognised as an enabler in every case of delivering healthy planning and active lifestyle initiatives.

A commonly identified aspect of internal LG functioning that acted as a barrier was limited LG practitioner knowledge regarding concepts of community health promotion, with practitioners unaware of such concepts holding potential health-affecting roles in LGs (refer to Table 1). Further, siloed operation within LG, both inter-departmental and intra-departmental was identified as being detrimental to LG operation and ability to implement such initiatives. 
Table 1. Internal LG functioning qualitative finding extracts

\begin{tabular}{|c|c|c|}
\hline Finding & Quote Extract & Respondent \\
\hline $\begin{array}{l}\text { Limited } \\
\text { practitioner } \\
\text { knowledge }\end{array}$ & $\begin{array}{c}\text { 'many planners }[\ldots] \text { still don't see the connection between their work and } \\
\text { peoples' health' }\end{array}$ & BE1 \\
\hline \multirow[t]{2}{*}{$\begin{array}{l}\text { Siloed LG } \\
\text { operation }\end{array}$} & $\begin{array}{l}\text { 'the challenge is to get the organisation to understand that health is everyone's } \\
\text { business' }\end{array}$ & $\mathrm{CH} 1$ \\
\hline & $\begin{array}{l}\text { 'A lack of integration and cooperation' makes it 'very easy for people to focus on } \\
\text { their own areas and continue the business as usual approach' }\end{array}$ & BE1 \\
\hline $\begin{array}{l}\text { Active } \\
\text { uptake and } \\
\text { partnership } \\
\text { formation }\end{array}$ & $\begin{array}{l}\text { Assisted by and evident through 'increased knowledge and understanding of the } \\
\text { issue and the role that planning must play' amongst LG staff }\end{array}$ & BE1 \\
\hline \multirow{3}{*}{$\begin{array}{l}\text { Framing of } \\
\text { health as a } \\
\text { shared } \\
\text { responsibility }\end{array}$} & $\begin{array}{l}\text { 'ensuring that my team and I are not viewed as the primary 'owner' of Council's } \\
\text { health and wellbeing response - it needs to be viewed as a shared responsibility' }\end{array}$ & $\mathrm{CH} 2$ \\
\hline & $\begin{array}{l}\text { Functioning that allows for 'a supportive and informed group of councillors and a } \\
\text { strong culture of working across the organisation' including 'people that can work } \\
\text { [to] transcend high level strategic thinking [and] planning and detailed design } \\
\text { [and] implementation' }\end{array}$ & BE1 \\
\hline & An environment where '[s]taff are generally all on the same page' & BE2 \\
\hline $\begin{array}{l}\text { Supportive } \\
\text { policy } \\
\text { framework }\end{array}$ & $\begin{array}{c}\text { 'The current policy framework is integral in implementing such projects and our } \\
\text { work is often highlighting many principles and achieving countless objectives } \\
\text { documented in the policies' }\end{array}$ & $\mathrm{CH} 3$ \\
\hline
\end{tabular}

Nevertheless, these barriers could generally be overcome where there was active take up internally from staff and where partnerships (refer also to Section 3.3) were pursued. Such partnerships were identified as forming either between various departments within a LG, or with LG and external stakeholders. Both partnership types led to improved operation and cooperation within the LG, while also breaking down existing siloed operations.

Another contributor to initiative implementation was the framing of community health as a 'shared responsibility' [CH2] among LG departments such as transport and land use. This included LG functioning that placed a mandate for action on both non-elected practitioners and elected officials (councillors), and the need for an organisational structure that fostered continued communication and cross-disciplinary discussion. In many instances this was formally facilitated, however cross-disciplinary communication was also determined by individual practitioner attributes in particular roles, and relationships between individuals within these roles.

A supportive policy framework was also identified as being present in all instances of successful implementation. Typically, roles in delivering healthy planning and active living initiatives were found to be supported through reference back to principles and objectives outlined in LG policy. This included where a LG's strategic direction specifically identified a project to be undertaken or where improvement of community health was an objective or aim generally. It also included situations where co-benefits, 'additional benefit[s] arising from an action that is undertaken for a different principal purpose' (Capon \& Rissel, 2010, 110), were identified as having strategic importance for the LG (refer also to Section 3.2). Vertically (between state and LG) and horizontally (inter-departmental) integrated planning was also noted to be assisted by LGs having municipal public health plans and by various other LG plans, policies and strategies. In numerous instances the creation of a municipal public health plan was identified as a key influence on the direction of overarching strategic plans, which in turn prompted relevant initiatives to be considered and undertaken [CH1, $\mathrm{CH} 2]$.

Internal LG operation can restrict project uptake through limited practitioner scope or siloed operation. In contrast, enablers to project uptake include how conducive LG operations are to partnership formation, the perception across a LG that community health is a shared responsibility, and through a supportive policy framework. Nevertheless, various other considerations also emerge as both barriers and enablers to project implementation in this field, as discussed below. 


\subsection{Promotion of Co-benefits as an Enabler}

The promotion of co-benefits was the second most commonly identified theme regarding project uptake. Perhaps unsurprisingly, no instances of promoting co-benefits of an initiative acting as a barrier were identified. Two scenarios whereby co-benefits were employed to promote healthy planning and active living initiatives were identified: one whereby a community health program is supported by other co-benefits such as to the economy or built environment, or conversely where community health is presented as a co-benefit of a project focusing on and undertaken primarily for reasons other than community health.

The range of co-benefits identified was broad and included delivery of various 'positive physical, social and economic benefits' [CH5]. Most initiatives were framed as being built environment projects undertaken for built form or economic reasons, with health impacts then presented as a co-benefit (refer to Table 2). Some LG's initiatives purposely omitted phrases such as 'health' and 'fitness', with these concepts being implicit program outcomes, with notions of 'feeling good', 'fun' and 'friends' instead forming the impetus for projects when discussed with the community [CH4].

Table 2. Promotion of co-benefits qualitative finding extracts

\begin{tabular}{|c|c|c|}
\hline Finding & Quote Extract & Respondent \\
\hline \multirow[t]{2}{*}{$\begin{array}{l}\text { Health as } \\
\text { co-benefit }\end{array}$} & $\begin{array}{l}\text { 'We were looking at ways in which we could make our city centre perform } \\
\text { better and }[\ldots . . .] \text { the research was also indicating that making the physical } \\
\text { environment more people friendly can also lead to better economic } \\
\text { performance, reduced environmental costs, improved social connectedness } \\
\text { and health and wellbeing. It was not conceived as a public health project - } \\
\text { however it was understood that this could be a positive outcome' }\end{array}$ & BE1 \\
\hline & $\begin{array}{l}\text { Community health 'is integrated into everything that we do, however it is } \\
\text { not always explicit (and may not need to be) [...] If [built environment } \\
\text { projects are] done well, the incidental activity will have health benefits' }\end{array}$ & BE1 \\
\hline
\end{tabular}

\begin{tabular}{lcc}
\hline $\begin{array}{l}\text { Economic } \\
\text { drivers or } \\
\text { co-benefits }\end{array}$ & $\begin{array}{c}\text { Initiatives framed as reducing 'duplication of services, [providing] financial benefit } \\
\text { with efficient use of resources (human and material) and ultimately [providing a] } \\
\text { service [that] is more effective' }\end{array}$ & CH6 \\
& $\begin{array}{c}\text { 'the initial interest came from concerns by councillors that this was a } \\
\text { low-performing council asset that required substantial financial subsidies from } \\
\text { council' }\end{array}$ & BE3 \\
& Active transport a 'low cost, or no cost' form of travel & BE8 \\
\hline $\begin{array}{l}\text { Built } \\
\text { environment } \\
\text { drivers or } \\
\text { co-benefits }\end{array}$ & $\begin{array}{c}\text { 'creating a genuine community meeting place' and 'activation of the public realm' } \\
\text { 'slower traffic, increased pedestrian permeability, safer intersections' and spaces } \\
\text { 'designed for people and not cars' }\end{array}$ & BE1, BE2 \\
\hline $\begin{array}{l}\text { Social } \\
\text { co-benefits }\end{array}$ & $\begin{array}{r}\text { 'opportunities for local employment and training' through to improving 'housing } \\
\text { diversity' and 'tackling [...] significant socio-economic disadvantage' }\end{array}$ & CH1 \\
& 'provid[e] the best opportunities for residents to enjoy healthy and connected lives \\
and flourish in their local community' & CH2
\end{tabular}

The fact that other considerations than health were generally responsible for project uptake was particularly apparent when economic co-benefits of projects were referenced, and where LGs were framed as an asset owner seeking to maximise the productivity of these resources such as through reducing duplication or improving efficiency. Such concepts were commonly identified as the source of LGs' initial interest in these initiatives.

Improved built environment outcomes were also oft-cited co-benefits of such projects. More commonly though, these outcomes formed the central impetus for program creation, with community health then acting as a co-benefit. Projects were noted as having positive built form outcomes including through facilitation of community interaction, improved settings for active transport and reduced traffic congestion. While these aspects can by extension promote more healthful behaviour such as active travel, practitioners (whether in community health or built environment roles) more commonly detailed built form changes such as these rather than 
population health changes resulting from projects.

Improved social outcomes were generally identified as a co-benefit of primarily economic and/or built form initiatives as discussed above. Such co-benefits ranged from employment opportunities through to improved liveability and social connectedness. It is noted that the associated benefits of such projects also extended to LGs themselves, such as improved internal functioning and the ability for the LG to gain recognition and positive attention (refer also to Section 3.4).

Each of the above co-benefits are ultimately contributors to community health when considered from a socio-ecological determinants perspective. This was generally acknowledged by respondents, who recognised 'the importance of considering all aspects of community health - infrastructure, social interaction, accessibility and affordability and the need [...] to get these right' [BE4]. Economic or built form benefits can therefore be considered significant enablers of projects, with both more commonly discussed than actual health outcomes.

\subsection{Partnerships as Enablers}

As identified in Section 3.1, partnerships were commonly identified as a 'useful strategy' to overcome siloed LG functioning [CH4]. Partnerships involving LGs were only identified as an enabler. The possibility that ineffectual partnerships, partnership breakdown or a lack of partnership formation might act as a barrier is noted, however is outside the scope of this study given only respondents involved in successful cases of implementation were sought.

Types of partnerships identified as being beneficial varied greatly and included projects undertaken across LG departments, projects guided by interdisciplinary internal advisory groups, partnerships with community sector service providers, partnerships with local commercial operators [CH7] and private developers [BE4], partnerships between multiple LGs [CH8], state government-led guidance (with LG as implementer) [CH5] and federal government-initiated partnerships (primarily funding partnerships, again with LG as implementer) [CH7] Such partnerships were multifaceted and complex, and no particular strategy or consistently identified enablers for partnership development emerged from the data. Instead, partnerships appeared to develop on an ad hoc and largely opportunistic basis. Nevertheless, the importance of partnership formation and cooperation in this re-emerging field was commonly recognised by respondents (refer to Table 3 ).

Table 3. Partnerships qualitative finding extracts

\begin{tabular}{lcc}
\hline Finding & Quote Extract & Respondent \\
\hline $\begin{array}{l}\text { Importance } \\
\text { of } \\
\text { partnerships, } \\
\text { collaboration }\end{array}$ & $\begin{array}{r}\text { 'Disease prevention can involve collaboration amongst professions, providers and } \\
\text { institutions which have traditionally been separate. Engagement, coordination and } \\
\text { collaboration are key' }\end{array}$ & CH6 \\
\hline $\begin{array}{l}\text { LGs 'open' } \\
\text { to }\end{array}$ & $\begin{array}{r}\text { '[LG] supports working with all industry sectors (government, private developers) } \\
\text { partnerships }\end{array}$ & $\begin{array}{r}\text { to achieve the best possible outcomes for its residents. Any pieces of work that } \\
\text { assist Council in achieving its objectives are welcomed' }\end{array}$ \\
\hline
\end{tabular}

Multiple benefits of forming partnerships both for the LG and for overall community health were identified, and respondents commonly positioned their LG as being open to new and innovative partnerships. The necessity of local partnerships in the successful implementation of initiatives is particularly noted. While partnerships with 'higher' (state and federal) levels of government in some instances provided funding to LGs, local partnerships, either internally within the LG or with external stakeholders, were identified as an enabling factor in almost every instance of implementation.

\subsection{Recognition and 'Good News' as an Enabler}

The majority of respondents identified positivity that such initiatives created and the recognition that comes along with an LG implementing these. Such recognition was identified as coming through awards, identification of the LG as engaging in best practice, or through community or media feedback and perceptions of the LG generally.

The political viability of healthy planning and active living initiatives at the LG level (refer to Table 4) was closely linked to the 'good news' aspects of such initiatives [BE5]. Where initiatives were successfully implemented they were also seen as achievements that the whole organisation could claim. Also associated with 
this notion of achievement was a sense of 'healthy' competitiveness, with LGs striving to be seen as innovative and as taking a proactive role in leading their community [CH8].

Table 4. Recognition and 'Good News' qualitative finding extracts

\begin{tabular}{|c|c|c|}
\hline Finding & Quote Extract & Respondent \\
\hline $\begin{array}{l}\text { Initiatives } \\
\text { politically } \\
\text { viable, } \\
\text { supported }\end{array}$ & 'Current local members and executive management very supportive' & CH6 \\
\hline \multirow{4}{*}{$\begin{array}{l}\text { Positivity } \\
\text { around LG's } \\
\text { role in } \\
\text { initiatives }\end{array}$} & 'We were very proud of our project' & BE6 \\
\hline & $\begin{array}{c}\text { 'The project allowed us to summarise and celebrate some of our successes and } \\
\text { subsequently be acknowledged at the State and National level' }\end{array}$ & $\mathrm{CH} 4$ \\
\hline & $\begin{array}{c}\text { 'It was }[\ldots] \text { a great way to remind the community of progress, and celebrate the } \\
\text { ongoing participation in projects' }\end{array}$ & BE7 \\
\hline & 'A ground breaking initiative that is a first for a regional Council in [the state]' & $\mathrm{CH} 5$ \\
\hline $\begin{array}{l}\text { Positivity } \\
\text { supporting, } \\
\text { rather than } \\
\text { driving, } \\
\text { projects }\end{array}$ & 'the kudos that went with [the project is] a bonus' & BE4 \\
\hline $\begin{array}{l}\text { Most } \\
\text { commonly } \\
\text { considered by } \\
\text { elected } \\
\text { members of } \\
\text { LG, politicians }\end{array}$ & $\begin{array}{l}\text { Initiatives are 'very visible, [with] lots of opportunities for our Mayor and } \\
\text { councillors to be photographed with the community' and '[l]ots of good news } \\
\text { stories for the media' }\end{array}$ & $\mathrm{CH} 1$ \\
\hline
\end{tabular}

Various positive phrases were used in discussing LG's roles in the initiatives. Such positivity revolved around pride, celebration, and a showcasing and acknowledgement of LG's efforts. This positive message was presented as a subsequent consideration and generally was not identified as driving initial interest in any project, although the good news aspect of such projects was identified as providing momentum after initial project implementation. Such positive recognition was generally considered most desirable to elected members and politicians.

\subsection{LG's Mandate as both Barrier and Enabler}

As discussed in Section 1, LG in Australia can be viewed as having always had community health as a core function, whether this is explicitly acknowledged or not. Nevertheless, perceptions surrounding whether 'community health' is influenced by, of concern to, or the responsibility of LG impact project initiation. Such perceptions can either support or limit project uptake.

A commonly identified barrier was the questioning of LGs' role in the provision of healthy planning and active living initiatives, with such questioning occurring both within LG, by practitioners or elected members, and throughout the community (refer to Table 5). Where the community was identified as questioning LG's mandate, this was considered to be due to a limited conceptual definition of 'health' (Note 3), and difficulty in reconciling with a socio-ecological perspective. Such a barrier also extended to attitudes of practitioners within LGs (refer to Section 3.1). 
Table 5. LG's mandate qualitative finding extracts

\begin{tabular}{|c|c|c|}
\hline Finding & Quote Extract & Respondent \\
\hline \multirow[t]{2}{*}{$\begin{array}{l}\text { Questioning } \\
\text { LG's role- } \\
\text { community }\end{array}$} & $\begin{array}{l}\text { 'Many in the community were not aware of the connections between the design } \\
\text { of the physical environment and how it can influence your likelihood to walk } \\
\text { or cycle more or less. Some community members are sceptical of local } \\
\text { governments' role in seeking to influence peoples' behaviour.' }\end{array}$ & BE1 \\
\hline & $\begin{array}{c}\text { Lack of '[p]olitical acceptance that local government has a role to play in terms } \\
\text { of contributing to the health of the community' }\end{array}$ & $\mathrm{BE} 4$ \\
\hline $\begin{array}{l}\text { Questioning } \\
\text { LG's role- } \\
\text { within LG }\end{array}$ & $\begin{array}{c}\text { Need for 'increas[ed] awareness amongst Councillors and staff that Local } \\
\text { Government has a role to play in promoting community health rather than just } \\
\text { being a provider of facilities' }\end{array}$ & $\mathrm{BE} 4$ \\
\hline \multirow[t]{2}{*}{$\begin{array}{l}\text { Responsibility } \\
\text { transfer }\end{array}$} & $\begin{array}{l}\text { 'Local government is always concerned about [cost and responsibility transfer]. } \\
\text { Local government needs support to implement programs that are broader than } \\
\text { [the] funding scope was designed to accommodate' }\end{array}$ & $\mathrm{CH} 9$ \\
\hline & $\begin{array}{c}\text { 'State government discharging responsibility for health to local government } \\
\text { without appropriate funding in place' }\end{array}$ & $\mathrm{CH} 5$ \\
\hline \multirow{2}{*}{$\begin{array}{l}\text { Use of } \\
\text { socio-ecological } \\
\text { determinants } \\
\text { perspective to } \\
\text { provide } \\
\text { mandate }\end{array}$} & $\begin{array}{l}\text { 'Almost all Council services' framed as being 'aimed at improving or } \\
\text { protecting public health, from bike paths that support physical wellbeing to } \\
\text { men's sheds that enhance emotional and psychological wellbeing' }\end{array}$ & CH5 \\
\hline & $\begin{array}{l}\text { 'Health in local government is based on the social determinants of health } \\
\text { model and on creating environments for health. It intersects across most work } \\
\text { in local government so the role of health planning is to support the joining of } \\
\text { the dots' }\end{array}$ & $\mathrm{CH} 1$ \\
\hline
\end{tabular}

There was also the perception amongst numerous practitioners in LG (both respondents and colleagues identified by respondents) that any impetus placed on LG in community health promotion amounted to responsibility transfer from 'higher' tiers of government. Responsibility transfer was most commonly identified as coming from state governments, which are generally responsible for providing and funding clinical healthcare in Australia. However, despite perceptions of responsibility transfer, an associated enabler to project support was the use of a socio-ecological determinants model to clearly mandate a role for LG in this field. Such a perspective was evident in the majority of responses, and was seen to encompass most roles performed by LG.

The level of impetus placed on LG for action in this field determined whether this consideration was a barrier or enabler to project implementation. Where practitioners or the community were unsure of LG's role in community health promotion, project implementation was made more difficult. Alternatively, where LG's role was considered central in addressing community health, or where the good news value of previous projects created a positive inertia going forward, project implementation was assisted.

\subsection{Funding and Resourcing as both Barrier and Enabler}

Compounding the impacts of those barriers identified in Sections 3.1 and 3.5 was the overarching consideration of LG funding and resourcing. Particularly relating to responsibility transfer, concerns were raised regarding an increased LG mandate in the field, often with no rearrangement to existing funding or resource allocation. Respondents identified program efficacy, community consultation, education programs, research and staffing to be constrained by resourcing. The largest barrier to incorporating health into practitioners' roles was '[a]ccessing funding' [BE6], as too was the primary barrier to implementation of such initiatives (refer to Table 6). Limits to funding and capacity were identified as a barrier to future projects even where other enablers such as those outlined in Sections 3.1 to 3.5 were present. For instance, in a case where a previous project allowed for 'greater awareness of health considerations in the organisation, the limits on capacity remain[ed]' a barrier [BE7]. 
Table 6. Funding and resourcing qualitative finding extracts

\begin{tabular}{lcc}
\hline Finding & Quote Extract & Respondent \\
& Primary barrier to implementation of initiatives 'is, and always will be, funding \\
and resourcing' & BE6 \\
funding & $\begin{array}{c}\text { anitiative 'would not have been possible without the [one-off] funding', } \\
\text { opportunities for such are 'extremely rare' }\end{array}$ & BE6, BE7 \\
\hline $\begin{array}{l}\text { Funding } \\
\text { provision }\end{array}$ & \begin{tabular}{l} 
opher \\
\hline
\end{tabular} &
\end{tabular}

It follows that where limited funding acts a barrier, provision of funding will be identified as an enabler, with many cases identified as achieving success only following provision of funding, generally through one-off or ad hoc arrangements. Limited resourcing and funding was however noted to encourage LGs and individual practitioners to pursue unique funding opportunities or approaches. Multiple projects identified were supported through private funding including private developers (reaffirming the value of local partnerships as per Section 3.3) and businesses.

\section{Discussion}

The emergence of six central themes regarding healthy planning and active living initiative implementation at the LG level is identified, with three themes having potential to act as barriers (internal LG functioning, LG's mandate for action in this field and limits to funding and resourcing), and all six having potential as enablers. Examining these barriers and enablers in isolation is, however, to simplify a complex set of interactions within and external to the bureaucratic agency of LG (Stoker, 2011). This section then attempts to further contextualise and examine some of the key findings identified in Section 3.

Firstly, it is noted that where siloed LG operations were existing they were not a prohibitive barrier to project implementation. Where other enablers (often the promotion of co-benefits) led to project uptake, this was generally noted to result in a positive cycle of silo breakdown, improved LG functioning and improved subsequent or continued project delivery. Further, while the strategic direction of each LG was considered an important enabler in allowing for healthy planning and active living initiatives' implementation, such strategic directions and guidance relating to these were regularly noted to be principles only, and so easily ignored. This was able to be addressed, however, through consideration of co-benefits, where health-promoting initiatives could be tied into alternative issues around which LGs did have specific policies or objectives.

The relative complexity of the relationship between community health and the built environment (see, for instance, Kent, Thompson, \& Jalaludin, 2011), particularly when the contextual and site-specific, geographic and population differences among LGs represented are considered, is noted. Combined with limits to funding and resourcing, this situation can create difficulties in monitoring and measuring precise health benefits of a single program. As a response, many LGs were found to present and discuss initiative participation rates and some key successes regarding general notions of improved community wellbeing or quality of life, rather than presenting more rigorous health findings from projects (such as, for example, the longitudinal study by Giles-Corti et al., 2013). This then led to LGs and respondents having a greater focus on the co-benefits of initiatives for their community (Giles-Corti, Foster, Shilton, \& Falconer, 2010). Also of consideration is time: planning timeframes are long, as are the beneficial health impacts of such projects, while Australian political cycles, including at LG level, are comparatively short (Hambleton, 2011). Co-benefits in this instance present a way for LGs to show more immediate benefits and 'good news' surrounding a project to their constituency.

It is acknowledged that the importance of partnerships in this field is not a novel finding (Kent \& Thompson, 2012; Thompson, Kent, \& Lyons, 2014), and reflects a re-emergence of the previous close partnership between the planning and health professions (Freestone \& Wheeler, 2015). Indeed, the formation of partnerships has been noted as a way for 'wicked [...s]patially concentrated problems' to be overcome through 'place sensitive, holistic approaches $[\ldots]$ delivered through networked relations crossing program silos, even jurisdictional turfs' (Bradford, 2004, 40). The findings outlined above reflect this notion, as the development of partnerships allowed for a breakdown of siloed operation in LGs, and partnerships have previously been noted as both a response and contributor to complexity (Sinclair, 2011, 78). LG is also identified as a level of government capable of addressing a 'multiplicity of factors' (Chandler, 2010, 13). Partnership formation can be seen as an effective way to address this multiplicity.

Further to the above ideas of complexity and multiplicity, the findings also reflect Stoker's $(2011,23)$ 'boundary 
problems' in public policy, whereby 'the boundaries between sectors of life and different institutions have become increasingly blurred'. Stoker's $(2011,23)$ example of this is illustrative, and has relevance to the healthy planning and active living field: does the mandate for health rest with the 'citizen who should eat and drink appropriately, the state that should provide good advice or companies that should sell healthier food'? Similarly, such questions of framing were found to be relevant considerations in determining whether there was a mandate for LGs to act in this space, either from the community, LG practitioners or from higher levels of government. Where LG was framed as playing a central role in influencing the health of their constituents, project implementation was assisted.

With regards to funding, both limited funding for initiatives and to LGs generally were found to have detrimental impacts to project implementation. Further, while the 'adaptive capacity' of LGs in demonstrating 'innovation and creativity' (Platts-Fowler \& Robinson, 2016, 763) to secure funding is noted as an enabler in Section 3.6, this scenario can be seen to further entrench health inequalities, as ad hoc funding opportunities present themselves to some LGs and not others, and to some areas within an LG and not others. Such ad hoc adoption occurs at the expense of sustainable, evidence based implementation of projects. This reflects the findings of Pettman et al. $(2013,73)$, who found in the 'health policy and practice' sector of Australian LG that 'the extent to which LGs are being supported externally [...] to implement evidence-informed initiatives, and guidance as to how to integrate these initiatives with existing health plans, has also been inconsistent.' Ad hoc, inconsistent and short-term funding opportunities and the need to form partnerships to secure such funding sits in sharp contrast with state government functioning in Australia, whereby health funding is supported through established mechanisms (see for instance, Section 5 'Health Cluster', New South Wales Government, 2017).

For LGs these findings have relevance given internal LG functioning was just one of six major themes emergent as impacting on project uptake. This indicates a significant role being played by external factors as well as reliance on individual staff members in key roles within a LG for successful implementation. Further, findings show that at an individual level, practitioners in this space require engagement not just in development of policy, but in the political and problem (framing) aspects as well.

Though undertaken in Australia, this research is hoped to have relevance to practitioners and policy makers in similar governmental or institutional settings, and in countries facing similar issues (i.e., automobile dependence; increasing prevalence of NCDs). The broad scope of the six themes increases their likelihood of transferability, though opportunities for similar studies in other parts of the world, or more localised studies in Australia might be avenues for future research.

\section{Conclusion}

This research, through surveys with 20 Australian LGs has determined six key barriers and enablers to project uptake in the healthy planning and active living space at a LG scale in Australia: (1) internal LG functioning, (2) the promotion of co-benefits, (3) partnerships, (4) the value of recognition and good news, (5) placing a mandate for action on LG and (6) funding and resourcing. While practical concepts and themes were emergent from LG practitioners in relation to particular projects, the findings reveal that implementation of projects also face underlying and structural barriers such as ad hoc funding provision, responsibility transfer and the need to rely on political and problem (framing) considerations in addition to policy development and implementation. This dependence of projects' success on the engagement of individual LG practitioners in politics and problem framing in addition to policy development and implementation indicates that the re-emerging field of healthy planning and active living promotion has not yet been integrated into the day-to-day functioning of Australian LG, despite states increasingly placing an emphasis on action at this level, and calls for such in relevant guidance, advocacy and literature.

\section{Acknowledgments}

This work was supported by the Australian Postgraduate Award (APA) and Curtin Research Scholarship (APA-CRS).

\section{References}

ALGA (Australian Local Government Association), National Heart Foundation of Australia, \& PIA (Planning Institute of Australia). (2009). Healthy spaces and places: A national guide to designing places for healthy living. Retrieved from http://www.healthyplaces.org.au/site/index.php

Allender, S., Cavill, N., Parker, M., \& Foster, C. (2009a). 'Tell us something we don't already know or do!' The response of planning and transport professionals to public health guidance on the built environment and physical activity. Journal of Public Health Policy, 30(1), 102-16. https://doi.org/10.1057/jphp.2008.43 
Allender, S., Gleeson, E., Crammond, B., Sacks, G., Lawrence, M., Peeters, A., Loff, B., \& Swinburn, B. (2011). Policy change to create supportive environments for physical activity and healthy eating: Which options are the most realistic for local government?. Health Promotion International, 27(2), 261-74. https://doi.org/10.1093/heapro/dar018

Allender, S., Gleeson, E., Crammond, B., Sacks, G., Lawrence, M., Peeters, ... Swinburn, B. (2009b). Moving beyond 'rates, roads and rubbish': How do local governments make choices about healthy public policy to prevent obesity?. Australia and New Zealand Health Policy, 6(20). https://doi.org/10.1186/1743-8462-6-20

Allmendinger, P., \& Haughton, G. (2013). Revisiting...spatial planning, devolution, and new planning spaces. Environment and Plannning C: Government and Policy, 28, 803-18. https://doi.org/10.1068/c09163

Aulich, C. (2015). Recognising the local government sector. In B. Dollery, \& I. Tiley (Eds.), Perspectives on Australian local government reform (pp. 162-75). Annandale: The Federation Press.

Bradford, N. (2004). Place matters and multi-level governance: Perspectives on a new urban policy paradigm. Policy Options, 25(2), 39-44.

Browne, G. R., Davern, M. T., \& Giles-Corti, B. (2016). An analysis of local government health policy against state priorities and a social determinants framework. Australia New Zealand Public Health, 40(2), 126-31. https://doi.org/10.1111/1753-6405.12463

Butterworth, I. (2009). Building community capacity through Municipal Public Health Planning. Planning News, $35(6), 18-21$.

Capon, A. G., \& Rissel, C. E. (2010). Chronic disease and climate change: Understanding co-benefits and their policy implications. NSW Public Health Bulletin, 21(5-6), 109-13.

Carter, S. M., \& Little, M. (2007). Justifying knowledge, justifying method, taking action: Epistemologies, methodologies, and methods in qualitative research. Qualitative Health Research, 17, 1316-28. https://doi.org/10.1177/1049732307306927

Chandler, J. (2010). A rationale for local government. Local Government Studies, 36(1), 5-20. https://doi.org/10.1080/03003930903445657

Chapman, P., \& Davey, P. (1997). Working 'with' communities, not 'on' them: A changing focus for local government health planning in Queensland. Australian Journal of Public Health-Interchange, 3(1), 82-91.

Christian, H., Knuiman, M., Bull, F., Timperio, A., Foster, S., Divitini, M., Middleton, N., \& Giles-Corti, B. (2013). New urban planning code's impact on walking: The Residential Environments Project. American Journal of Public Health, 103(7), 1219-28. https://doi.org/10.2105/AJPH.2013.301230

Cleland, V., McNeilly, B., Crawford, D., \& Ball, K. (2013). Obesity prevention programs and policies: Practitioner and policy-maker perceptions of feasibility and effectiveness. Obesity, 21, E448-E455. https://doi.org/10.1002/oby.20172

Dudey, G. (2013). Why do ideas succeed and fail over time? The role of narratives in policy windows and the case of the London congestion charge. European Public Policy, 20(8), 1139-1156. http://dx.doi.org/10.1080/13501763.2013.771090

Ewing, R., \& Handy, S. (2009). Measuring the unmeasurable: Urban design qualities related to walkability. Urban Design, 14(1), 65-84. https://doi.org/10.1080/13574800802451155

Frank, L. D., Andresen, M. A., \& Schmid, T. L. (2004). Obesity relationships with community design, physical activity, and time spent in cars. American Journal of Preventive Medicine, 27(2), 87-96. https://doi.org/10.1016/j.amepre.2004.04.011

Freestone, R., \& Wheeler, A. (2015). Integrating health into town planning: A history. In H. Barton, S. Thompson, S. Burgess, \& M. Grant (Eds.), The Routledge handbook of planning for health and well-being: Shaping a sustainable and healthy future (pp. 17-36). Oxon: Routledge.

Giles-Corti, B., Badland, H., Mavoa, S., Turrell, G., Bull, F., Boruff, B., ... Thackway, S. (2014). Reconnecting urban planning with health: A protocol for the development and validation of national liveability indicators associated with noncommunicable disease risk behaviours and health outcomes. Public Health Research and Practice, 25(1), 1-5. http://dx.doi.org/10.17061/phrp2511405

Giles-Corti, B., Bull, F., Knuiman, M., McCormack, G., Van Niel, K., Timperio, A., ... Boruff, B. (2013). The influence of urban design on neighbourhood walking following residential relocation: Longitudinal results 
from the RESIDE study. Social Science and Medicine, $77(1), \quad 20-30$. https://doi.org/10.1016/j.socscimed.2012.10.016

Giles-Corti, B., Foster, S., Shilton, T., \& Falconer R. (2010). The co-benefits for health of investing in active transportation. NSW Public Health Bulletin, 21(5-6), 122-7. https://doi.org/10.1071/NB10027

Giles-Corti, B., Sallis, J. F., Sugiyama, T., Frank, L. D., Lowe, M., \& Owen, N. (2015). Translating active living research into policy and practice: One important pathway to chronic disease prevention. Journal of Public Health Policy, 36, 231-243. http://dx.doi.org/10.1057/jphp.2014.53

Grant, B., Dollery, B., \& Kortt. M. (2016). Recasting leadership reform in Australian local government: A typology from political theory. Local Government Studies, 42(6), 1024-46. https://doi.org/10.1080/03003930.2013.861820

Hambleton, R. (2011). Place-based leadership in a global era. Commonwealth Journal of Local Governance, 8/9, 8-32.

Harris, P., Kent, J., Sainsbury, P., \& Thow, A. M. (2016). Framing health for land-use planning legislation: A qualitative descriptive content analysis. Social Science \& Medicine, 148, $42-51$. https://doi.org/10.1016/j.socscimed.2015.11.029

Healey, P. (2010). Making better places: The planning project in the twenty-first century. Houndmills, Bassingstoke: Palgrave Macmillan.

Healthy Active by Design. (2017). Healthy Active by Design national website launch. Retrieved from http://www.healthyactivebydesign.com.au/news/healthy-active-design-national-website-launch

Henstra, D. (2010). Explaining local policy choices: A multiple streams analysis of municipal emergency management. Canadian Public Administration, $241-58$. https://doi.org/10.1111/j.1754-7121.2010.00128.x

Jolley, G., \& Barton, E. (2015). Local government capacity to deliver health promotion initiatives: A case study Letter. Health Promotion Journal of Australia, 26, 159-60. https://doi.org/10.1071/HE14083

Kent, J., Thompson, S. M., \& Jalaludin, B. (2011). Healthy built environments: A review of the literature. Sydney: Healthy Built Environments Program, City Futures Research Centre, UNSW.

Kent, J., \& Thompson, S. (2012). Health and the built environment: Exploring foundations for a new interdisciplinary profession. Environmental and Public Health. https://doi.org/10.1155/2012/958175

Kingdon, J. W. (2003). Agendas, alternatives, and public policies (2nd ed.). New York: Longman.

Kurko, J., \& Holden, G. (2012). The built environment and public health: From theory to practice. Paper presented at the 46th Annual Conference of the Architectural Science Association, Gold Coast.

Lawless, A., Lane, A., Lewis, F., Baum, F., \& Harris, P. (2017). Social determinants of health and local government: Understanding and uptake of ideas in two Australian states. Australia New Zealand Public Health, 41, 204-9. https://doi.org/10.1111/1753-6405.12584

Lette, J. (2011). Development and active living: Designing projects for active living - developer's checklist with case studies. NSW Premier's Council for Active Living \& BBC Consulting Planners.

Lowe, M., Whitzman, C., \& Giles-Corti, B. (2017). Health-promoting spatial planning: Approaches for strengthening urban policy integration. Planning Theory \& Practice. https://doi.org/10.1080/14649357.2017.1407820

Matan, A., Newman, P., Trubka, R., Beattie, C., \& Selvey, L. A. (2015). Health, transport and urban planning: Quantifying the links between urban assessment models and human health. Urban Policy and Research, 1-15. https://doi.org/10.1080/08111146.2014.990626

National Heart Foundation of Australia. (2009). Healthy by Design: A guide to planning and designing environments for active living in Tasmania. National Heart Foundation of Australia.

National Heart Foundation of Australia. (2012). Active living impact checklist - A tool for developments in the Australian Capital Territory. Canberra: National Heart Foundation of Australia.

New South Wales Government. (2017). Budget estimates 2017-18. Sydney: New South Wales Government.

NSW Department of Health. (2009). Healthy urban development checklist: A guide for health services when commenting on development policies, plans and proposals. Sydney: NSW Department of Health. 
Pettman, T. L., Armstrong, R., Pollard, B., Evans, R., Stirrat, A., Scott, I., Davies-Jackson, G., \& Waters, E. (2013). Using evidence in health promotion in local government: Contextual realities and opportunities. Health Promotion Journal of Australia, 24, 72-5. https://doi.org/10.1071/HE12902

Platts-Fowler, D., \& Robinson, D. (2016). Community resilience: A policy tool for local government?. Local Government Studies, 42(5), 762-84. https://doi.org/10.1080/03003930.2016.1186653

Premier's Council for Active Living. (2012). Designing places for active living. Retrieved from http://www.pcal.nsw.gov.au/planning_and_design_guidelines

Rissel, C., \& McCue, P. (2014). Healthy places and spaces: The impact of the built environment and active transport on physical activity and population health. Health Promotion Journal of Australia, 25, 155-6. https://doi.org/10.1071/HE14103

Roberto, C. A., Swinburn, B., Hawkes, C., Huang, T. T. K., Costa, S. A., Ashe, M., Zwicker, L,. Cawley, J. H., \& Brownell, K. D. (2015). Patchy progress on obesity prevention: Emerging examples, entrenched barriers, and new thinking. The Lancet, 285(1), 2400-9. https://doi.org/10.1016/S0140-6736(14)61744-X

Sinclair, S. (2011). Partnership or presence? Exploring the complexity of community planning. Local Government Studies, 37(1), 77-92. https://doi.org/10.1080/03003930.2010.548550

Smith, M. (2014). Integrating policies, plans and programmes in local government: An exploration from a spatial $\begin{array}{llll}\text { planning perspective. Local Government } & \text { Studies, }\end{array}$ https://doi.org/10.1080/03003930.2013.823407

Stoker, G. (2011). Was local governance such a good idea? A global comparative perspective. Public Administration, 89(1), 15-31. https://doi.org/10.1111/j.1467-9299.2011.01900.x

Stokols, D. (1992). Establishing and maintaining healthy environments: Toward a social ecology of health promotion. American Psychologist, 47(1), 6-22.

Swinburn, B., Egger, G., \& Raza, F. (1999). Dissecting obesogenic environments: The development and application of a framework for identifying and prioritizing environmental interventions for obesity. Preventive Medicine, 29(6), 563-70. https://doi.org/10.1006/pmed.1999.0585

Tenbensel, T., Eagle, S., \& Ashton, T. (2012). Comparing health policy agendas across eleven high income countries: Islands of difference in a sea of similarity. Health Policy, 106, 29-36. http://dx.doi.org/10.1016/j.healthpol.2012.04.011

Thompson, S., Kent, J., \& Lyons, C. (2013). Planning and health: Forging new alliances in building healthy and resilient cities. Paper presented at the Congress of Association of European Schools of Planning and Association of Collegiate Schools of Planning, Dublin, July.

Thompson, S., Kent, J., \& Lyons, C. (2014). Building partnerships for healthy environments: Research, leadership and education. Health Promotion Journal of Australia, 25, 202-8, https://doi.org/10.1071/HE14039

Thompson, S., \& McCue, P. (2016). Healthy planning: An evolving collaborative partnership. Urban Policy and Research. http://dx.doi.org/10.1080/08111146.2016.1140032

Thornberg, R. (2012). Informed grounded theory. Scandinavian Journal of Educational Research, 56(3), 243-259. http://dx.doi.org/10.1080/00313831.2011.581686

Wheeler, A. R., \& Thompson, S. M. (2010). The future health and environmental sustainability of South East Queensland: An evaluation of the Regional Plan. Australian Planner, 47(3), 152-61. https://doi.org/10.1080/07293682.2010.508203

Wiggins, D. (2008). Supportive environments: Utilising the NSW planning system to enable active living. Prepared for the NSW Premier's Council for Active Living.

Wiggins, D. (2013). Addressing active living and healthy eating through councils' Integrated Planning and Reporting Framework. Sydney: Prepared for the NSW Premier's Council for Active Living.

Williams, P., \& Maginn, P. J. (2012). Planning and governance. In S. Thompson \& P. Maginn (Eds.), Planning Australia: An overview of urban and regional planning. Cambridge: Cambridge University Press.

WHO (World Health Organisation), \& Secretariat of the Convention on Biological Diversity. (2015). Connecting global priorities: Biodiversity and human health: A state of knowledge review. Geneva: WHO \& Convention on Biological Diversity. 


\section{Notes}

Note 1. For brevity Australia's two primary mainland territories (Australian Capital Territory and Northern Territory) are included in the term 'states' as used throughout this article.

Note 2. Understanding of the terms 'barriers' and 'enablers' for the purposes of this study is consistent with the use of those terms by Smith (2014).

Note 3. WHO and Secretariat of the Convention on Biological Diversity (2015, xii) define human 'health' as 'a state of complete physical, mental and social well-being and not merely the absence of disease or infirmity'.

\section{Copyrights}

Copyright for this article is retained by the author(s), with first publication rights granted to the journal.

This is an open-access article distributed under the terms and conditions of the Creative Commons Attribution license (http://creativecommons.org/licenses/by/4.0/). 